\title{
Preface : Invited Issue Editor Professor Kyu-Chang Wang and Secondary Neurulation : The Current Central Topic in Spinal Dysraphism
}

\author{
Chae-Yong Kim, ${ }^{1,2}$ Seung-Ki Kim ${ }^{1,3}$ \\ Editor of the 'Pediatric Issue,", Journal of Korean Neurosurgical Society, Seoul, Korea \\ Chair, ${ }^{2}$ Publication Committee, Korean Society for Pediatric Neurosurgery, Seoul, Korea \\ President, ${ }^{3}$ Korean Society for Pediatric Neurosurgery, Seoul, Korea
}

Since 2015, the Korean Society for Pediatric Neurosurgery (KSPN) has published an official journal known as the Pediatric Issue as a supplement to the Journal of Korean Neurosurgical Society (JKNS), which is the official journal of the Korean Neurosurgical Society (KNS) ${ }^{2}$. The Pediatric Issue is published in May each year, particularly to honor Children's Day on May 5 and the annual meeting of the KSPN that is held in May. One of the figures presented in the Pediatric Issue is selected to be on the cover of the May issue of the journal.

The Pediatric Issue has made a significant contribution to the enhancement of the academic level of the JKNS, as well as the field of pediatric neurosurgery, by covering a wide range of topics from 2015 to 2020, such as Moyamoya disease (edited by Professor Kyu-Chang Wang and Seung-Ki Kim), craniosynostosis (invited editor : Professor Joon-Ki Kang), the era of neuroendoscopy (invited editor : Professor Joong-Uhn Choi), pediatric malignant brain cancers in the molecular era (invited editor : Professor James T. Rutka), pediatric epilepsy surgery (invited editor : Professor Byung-Kyu Cho), and changing concepts in spinal dysraphism during the last two decades (invited editor : Professor Dachling Pang). The topic of the 2021 JKNS : Pediatric Issue, i.e., secondary neurulation : the current central topic in spinal dysraphism, was organized by the issue's invited editor, Professor Kyu-Chang Wang, who is one of the internationally-acknowledged pioneers in the field

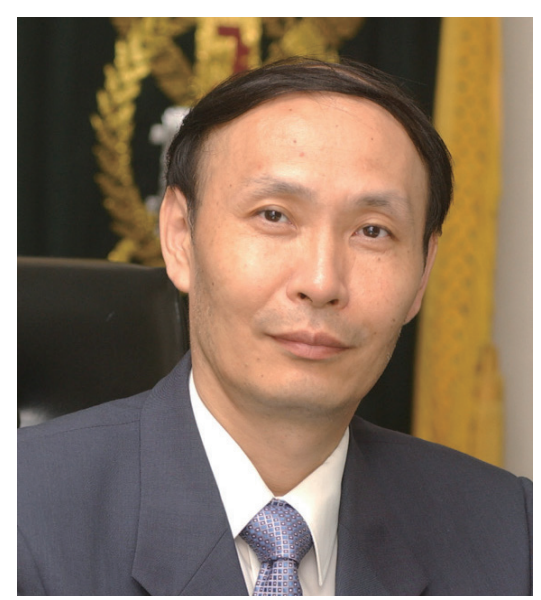

Fig. 1. Invited Issue Editor, Professor Kyu-Chang Wang taken when he was the Dean of Seoul National University College of Medicine, 2005.

- Received : March 6, $2021 \cdot$ Accepted: March 26, 2021

- Address for reprints : Seung-Ki Kim

Division of Pediatric Neurosurgery, Seoul National University Children's Hospital, Seoul National University College of Medicine, 101 Daehak-ro, Jongno-gu, Seoul 03080, Korea

Tel : +82-2-2072-2350, Fax : +82-2-744-8459, E-mail : nsthomas@snu.ac.kr, ORCID : https://orcid.org/0000-0002-0039-0083 
of spinal dysraphism (Fig. 1). This Pediatric Issue is the second part of spinal dysraphism. The first part was published in the 2020 JKNS : Pediatric Issue.

Professor Kyu-Chang Wang was born on November 1, 1954, and he graduated from Seoul National University College of Medicine (SNUCM) in 1979 with the Dean's Award, which is the second highest honor. He completed his internship and resident training at Seoul National University Hospital (SNUH) and also served 3 years in military service, as it is required of male citizens in Korea. In 1987, he became a member of the faculty of the Department of Neurosurgery in the SNUCM and SNUH. Professor Bo Sung Sim, Professor Wang' $s$ big boss and the founder of the Department of Neurosurgery at the SNUH, suggested him that he specialize in pediatric neurosurgery. Professor Byung-Kyu Cho (Fig. 2), Professor Wang's boss and the founder of the Division of Pediatric Neurosurgery at Seoul National University Children's Hospital, suggested him that he study congenital anomalies. From 1990 to 1992, he worked as a research fellow under the guidance of Dr. David G. McLone at Children's Memorial Hospital in Chicago.

Professor Wang has made a significant achievements in the development and globalization of Korean pediatric neurosurgery during his 32 years of service in his alma mater, $\mathrm{SNUH}-$ $\mathrm{CM}^{1}$, from 1987. In 2010, he hosted the annual meeting of International Society for Pediatric Neurosurgery (ISPN) at Jeju Island. In 2012 at ISPN's Sydney meeting, he was inaugurated as ISPN's 42nd president. During his term as president, he set an example of leadership, sincerity and responsibility. In 2013,

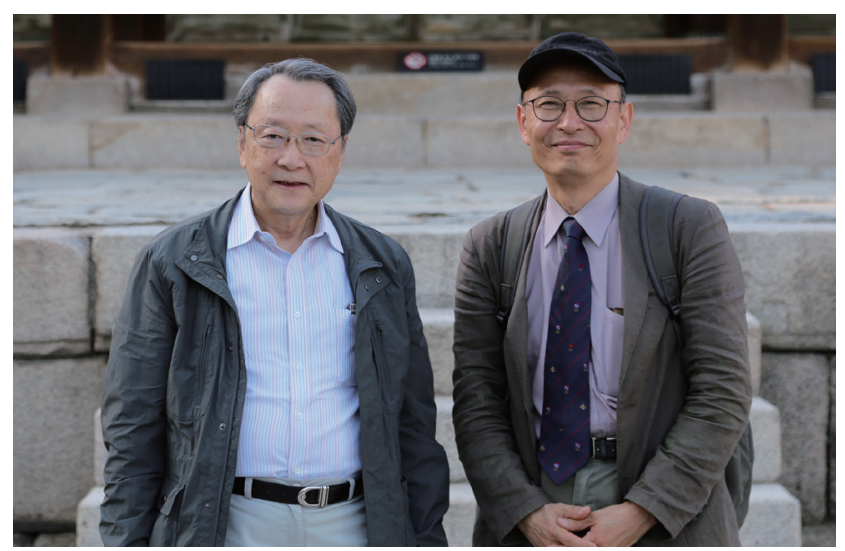

Fig. 2. Professor Byung-Kyu Cho and Professor Kyu-Chang Wang at Changgyeonggung Palace in spring. One of the reasons that Professor Wang chose to pursue his career in the field of pediatric neurosurgery was to work with Professor Cho, whom he wholeheartedly admired. he played a central role in the establishment of the Asian-Australasian Society for Pediatric Neurosurgery (AASPN) with Professor Tai-Tong Wong in Taiwan. Currently he is the President-Elect of AASPN.

In 1997, Professor Wang was appointed as the Director of the Department of Research Planning and Management, Clinical Research Institute (now renamed as the Biomedical Research Institute) at SNUH. In 2002, he became the Director of the Department of Education and Research at SNUH. In 2004, Professor Wang was elected the Dean of the SNUCM through the direct vote of all professors. He was the youngest dean ever elected in the history of the SNUCM. While carrying out various positions, he left a great legacy to medical students, residents and junior professors. Since 2021, he has served as a pediatric neurosurgeon at the Center for Rare Cancers, National Cancer Center in Kyounggi-do, Republic of Korea, mainly as a surgeon for pediatric brain tumors and a mentor for other neurosurgeons. He now lives in Yongin, Kyounggi-do with his wife, Eun-Mi Jung, and has a son named Tae-Ho Wang.

Professor Wang was invited to be the editor of the $2021 \mathrm{Pe}$ diatric Issue: Secondary neurulation : the current central topic in spinal dysraphism due to his remarkable contribution to the field.

Recent advances in the understanding of the anatomical pathology and pathoembryology of congenital disorders of the nervous system have led to changes in the classification and management of spinal dysraphism. The articles of this $P e-$ diatric Issue will undoubtedly provide readers with current concepts and future treatment guidelines for pediatric spinal dysraphism related to disorders of secondary neurulation. Ten articles were contributed by leading researchers in the field from France, Japan, the United Kingdom, and Korea. Professor Wang actively recruited world-class scholars to participate in the writing of this Pediatric Issue. Dr. Martin Catala of France provided an overview of secondary neurulation and Dr. Sayaka Dojima contributed a comprehensive anecdote on the "human tail". Dr. Yoshiko Takahashi provided a cell-level introduction for secondary neurulation, "Secondary neurulation: cell fate", and Dr. Dominic Thompson of the United Kingdom contributed an article on the pathophysiology and therapeutic strategy for split cord malformation and neurenteric cysts. Dr. Sun of Korea provided a detailed description of embryonal neuromesenchymal tissue for central nervous sys- 
tem from the view of anatomist. Professor Wang summarized contemporary and prospective perspectives at the end of the edition. Furthermore, he also recruited outstanding Korean scholars such as Dr. Ji Hoon Phi, Dr. Ji Yeoun Lee, and Dr. Kyung Hyun Kim.

We deeply appreciate brilliant minds from all over the world, who actively participated in the 2021 Pediatric Issue. Additionally, we would like to express our sincere gratitude to Professor Wang for his enthusiasm and dedication as the invited editor.

\section{CONFLICTS OF INTEREST}

No other potential conflict of interest relevant to this article was reported.

\section{AUTHOR CONTRIBUTIONS}

\section{Conceptualization : CYK, SKK}

Data curation : CYK
Formal analysis : CYK, SKK

Visualization : CYK, SKK

Writing - original draft : CYK, SKK

Writing - review \& editing : CYK, SKK

\section{ORCID}

Chae-Yong Kim https://orcid.org/0000-0001-9773-5553

Seung-Ki Kim https://orcid.org/0000-0002-0039-0083

\section{- Acknowledgements}

We deeply appreciate Mr. Eui Joon Kim for the English editing of this article.

\section{References}

1. Kim SK : Professor Kyu-Chang Wang: president of the ISPN, 2012-2013. Childs Nerv Syst 30 : 1775-1781, 2014

2. Kim SK, Wang KC : Preface to pediatric issue. J Korean Neurosurg Soc $57: 389,2015$ 